\title{
Effect of Different Silane Treatments on Long-Term Bonding Between Non-Etched Glass-Ceramic and Resin Cement
}

\section{Efecto de diferentes tratamientos con silano en la resistencia de unión entre cerámica vítrea no condicionada y cemento resinoso en largo plazo de almacenamiento}

\author{
Fabián Murillo-Gómez DDS, MSc¹,2; Mario F. De Goes DDS, MSc, PhD1 \\ 1. Department of Restorative Dentistry-Dental Materials Division, \\ Piracicaba School of Dentistry-Campinas State University, Piracicaba, São Paulo, Brazil. \\ 2. Department of Restorative Dentistry, School of Dentistry-University of Costa Rica, San José, Costa Rica. \\ Correspondence to: Dr. Mario Fernando De Goes - degoes@fop.unicamp.br \\ Received: 5-II-2017 \\ Accepted: 10-II-2017 \\ Published Online First: 14-II-2017
}

DOI: http://dx.doi.org/10.15517/ijds.v0i0.27950

\section{ABSTRACT}

The present study evaluated the bond strength between glass-ceramic and resin cement, using different silane treatments, performing no previous hydrofluoric acid (HF) etching on ceramic surface, after short- and long- term storage. One hundred and eighty glass-ceramic plaques (IPS e.max $C A D \otimes)$ were polished and divided into six groups $(n=30)$ to receive different silane treatments: (1) RCP-RelyX Ceramic Primer ${ }^{\circledR}$ (one-bottle silane), (2) RCP+SB-RelyX Ceramic Primer and Adper Singlebond ${ }^{\circledR}$ (silane plus separated adhesive), (3) SBU-Scotchbond Universal ${ }^{\circledR}$ (silane-containing universal adhesive), (4) CP-Clearfil Ceramic Primer® (silane/MDP primer), (5) NC-no-silane (negative control) and (6) PC-Previous HF etching $(5 \%, 20 s)$ plus RelyX Ceramic Primer $®$ (positive control). Two resin cement cylinders (Rely $X$ Ultimate $®$ ) were built on each plaque. Each group was divided into two sub-groups to be stored for 24 hours (24h) or 6 months $(6 \mathrm{mo})$ in distilled water at $37^{\circ} \mathrm{C}(\mathrm{n}=15)$. Then microshear ( $\mu \mathrm{SBS})$ testing was performed. Failure mode was analyzed using scanning electron microscopy (SEM). Data were statistically analyzed by two-way ANOVA and Tukey's test $(\alpha=0.05)$. Both factors and their interaction resulted statistically significant $(p \leq 0.05)$. PC obtained the highest $\mu S B S$ values (in MPa) at both storage times (24h: $28.11 \pm 2.44 ; 6 \mathrm{mo}$ : 19.10 \pm 3.85 ). After 24h storage, groups $\mathrm{RCP}+\mathrm{SB}(10.86 \pm 3.62), \mathrm{SBU}(8.37 \pm 4.33)$ and $\mathrm{CP}(8.05 \pm 3.62)$ were not statistically different from NC $(8.00 \pm 2.51)$; only RCP $(19.73 \pm 4.63)$ and PC obtained higher values. After 6 months, only PC showed higher values than NC $(0.04 \pm 0.01)$. Cohesive failure in resin cement was more prevalent for RCP-24h and PC, while adhesive failure was more frequent among all other groups. Clinical relevance: None of the commercially available silane primers tested, improve long- term ceramic/cement bonding without performing HF etching on ceramic surface. Combination of HF acid and silane, remain as a gold standard treatment for glass-ceramic materials.

MURILLO F., DE GOES M., 2017: Effect of Different Silane Treatments on Long-Term Bonding Between Non-Etched Glass-Ceramic and Resin Cement.-ODOVTOS-Int. J. Dental Sc., 19-2 (May-August): 33-46. 


\section{KEYWORDS \\ Silane; Glass-ceramics; Lithium disilicate; Multi-mode adhesives; Cementation; Ceramic bonding; Hydrofluoric acid.}

\section{RESUMEN}

Este estudio evaluó la resistencia de unión entre cerámica vítrea y cemento resinoso, utilizando diferentes tratamientos de silano, sin realizar condicionamiento previo de la cerámica con ácido fluorhídrico (HF), después de almacenamiento en corto y largo plazo. Ciento ochenta placas de cerámica (IPS e.max CADR) fueron pulidas y divididas en 6 grupos $(n=30)$ para ser tratadas como sigue: (1) RCP-

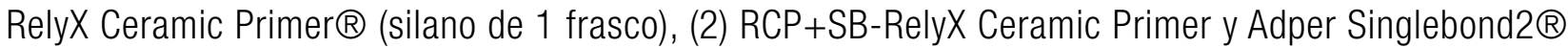
(silano más adhesivo separado), (3) SBU-Scotchbond Universal $®$ (adhesivo universal conteniendo silano), (4) CP-Clearfil Ceramic Primer $($ primer cerámico conteniendo silano y MDP), (5) NC-ningún silano (control negativo) y (6) PC-Condicionamiento con HF previo $(5 \%, 20$ s) y silano (RelyX Ceramic Primer $\circledR)$

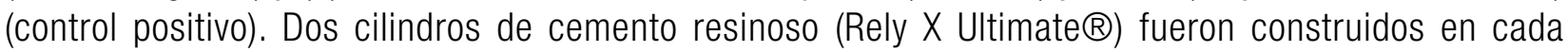
placa. Cada grupo fue dividido en 2 sub-grupos para ser almacenados por 24 horas (24h) y 6 meses (6mo) en agua destilada a $37^{\circ} \mathrm{C}(n=15)$. Luego fue realizada la prueba de microcizallamiento $(\mu S B S)$. El tipo de fractura fue analizado con microscopio electrónico de barrido (SEM) y los datos analizados con las pruebas estadísticas ANOVA de dos factores y Tukey $(\alpha=0.05)$. Ambos factores y su interacción resultaron estadísticamente significativos $(\mathrm{p} \leq 0.05)$. PC presentó los valores más altos de $\mu \mathrm{SBS}(\mathrm{MPa})$ para ambos tiempos de almacenamiento (24h: 28.11 $\pm 2.44 ; 6 \mathrm{mo:} 19.10 \pm 3.85)$. Luego de 24h, los grupos $\mathrm{RCP}+\mathrm{SB}(10.86 \pm 3.62)$, SBU $(8.37 \pm 4.33)$ y CP $(8.05 \pm 3.62)$ no fueron estadísticamente diferentes del

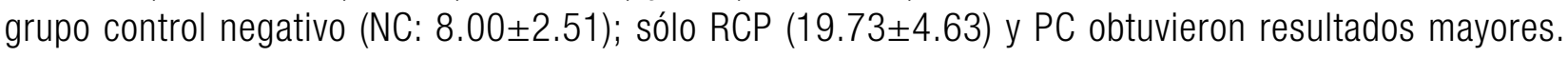
Después de 6 meses de almacenaje, sólo el grupo PC obtuvo valores estadísticamente mayores que NC (0.04 \pm 0.01$)$. Fractura cohesiva en el cemento fue más prevalente para RCP-24h y PC, mientras que el tipo adhesivo fue el más frecuente para todos los demás grupos. Relevancia Clínica: Ninguno de los tratamientos de silano evaluados, mejoró significativamente la adhesión a largo plazo entre cerámica vítrea no condicionada y cemento resinoso. La combinación de HF y silano, continúa siendo el tratamiento de preferencia para cerámica vítrea durante el proceso de cementación.

\section{PALABRAS CLAVE}

Silano; Cerámica vítrea; Disilicato de litio; Adhesivos universales; Cementación; Adhesión de cerámicas; Ácido fluorhídrico. 


\section{INTRODUCTION}

Glass-ceramic is nowadays one of the preferred materials for aesthetic indirect restorations, showing adequate optical and mechanical properties, among other benefits [1]. The dissimilar chemical nature of glass-ceramic and tooth structure, makes mandatory to use intermediate coupling agents to bond both surfaces [2]. Resin cement is considered the material of choice to bond ceramic with tooth as it can adhere chemically or mechanically to glassceramic surface, besides improving restorations' mechanical behavior $[3,4]$.

Mechanical strategy to bond glass-ceramic and resin cement may be achieved by performing a previous roughening, employing hydrofluoric acid (HF) on ceramic surface, which dissolves part of the glassy phase present on glass ceramic material, facilitating mechanical interlocking with resin cement $[3,5,6,7]$. On the other hand, silane primers can produce a chemical adhesion between resin cement and glass ceramic [3]. The combination of both mechanical and chemical strategies is considered the gold standard for resin-cement/ glass-ceramic bonding $[2,3,5]$. However, HF may be a dangerous substance [8], reason why some researchers have focused their studies in looking for an alternative glass-ceramic surface treatment, by avoiding the usage of HF [9]. In addition, some manufacturers indicate to use their silane primers alone, without HF [10], at the time that some works claim that using only a silane primer is enough to achieve a proper bonding between glass-ceramic and resin cement [11-13].

Silane-coupling agents must be hydrolyzed ( $\mathrm{SiOR} \longrightarrow \mathrm{SiOH})$ to bond with silicon on glassceramic surface [2]. So, many commercial silane-solutions use a pre-hydrolysed silane (3-Methacryloxypropyltrimethoxysilane, MPS) mixed with ethanol and water as solvents. This substance can form multimolecular-water resistant layers of 50-100nm within the glass-ceramic surface [14], which may chemically bond with methacrylate groups composing resin cements. Such bonding produces integrity among the system tooth/resin cement/restoration.

Other ceramic primers are commercially available, containing silane and phosphate acid monomers such as MDP (10-methacryloyloxydecyl dihydrogen phosphate). Those phosphate acid monomers are employed due to their capability to bond metallic molecules present in some ceramics (mainly non-glass ceramics) with methacrylate groups in resin cements $[15,16]$. Thus, those primers can improve resin cement adhesion to glass ceramics and polycrystalline ceramics. Additionally, some multi-mode adhesives have incorporated silane to their composition. This multi-mode solution is indicated for silanization of glass-ceramics, before cementation process in order to simplify the clinical steps. Manufacturers recommend this broad range of silane-containing solutions equally as conventional silane primers, but it is unclear if they behave similarly or not. It is also uncertain if one can avoid the use of $\mathrm{HF}$ when employing these variable silane-containing primers.

Here we evaluate the isolated effect of different silane-containing primers on non-etched glass-ceramic/resin cement bonding, after shortand long- term storage. The null hypothesis set is that silane primers or storage times tested do not affect glass-ceramic/resin cement bonding.

\section{MATERIALS AND METHODS}

Lithium disilicate glass-ceramic (IPS e-max CAD/CAM, Ivoclar, Vivadent, NY, USA; Lot. N76665) was used along with one resin cement (Rely XUltimate, 3M ESPE, ST. Paul, MN, USA; Lot. 505370) and three silane primers (Table 1). The specimen preparation methodology for the microshear bond strength test ( $\mu \mathrm{SBS})$ was adapted from the one developed by Shimada et al. [11]. A schematic representation of the study set up, is shown on Figure 1. 
One hundred and eighty lithium disilicate were ultrasonically cleaned for 5 minutes in ceramic plaques measuring $6 \pm 0.1 \mathrm{~mm}$ in length, 90\% alcohol. Then, specimens were dried and $3 \pm 0.1 \mathrm{~mm}$ in width and $2 \pm 0.1 \mathrm{~mm}$ in thickness were milled from CAD/CAM blocks on an E4D Dentist System (D4D technologies, LLC, Richardson, TX, USA) using a custom-mill file. The specimens covered with a pre-drilled (circle compartments, measuring $1 \mathrm{~mm}$ thick and $1 \mathrm{~mm}$ in diameter) double-face masking tape, to delimitate the bonding area (Fig. 1).

Table 1. Materials used in this study.

\begin{tabular}{|c|c|c|c|}
\hline Material & Lot. & Composition* & Manufacturer \\
\hline Rely X Ceramic Primer & N406850 & MPS, Ethanol, Water & 3M ESPE St. Paul, MN, USA \\
\hline Clearfil Ceramic Primer & 00023D & MPS, MDP, Ethanol & $\begin{array}{l}\text { Kuraray Noritake Dental Inc., } \\
\text { Okayama, Japan }\end{array}$ \\
\hline $\begin{array}{l}\text { Single Bond Universal Adhesive } \\
\text { (Scotchbond Universal in the USA) }\end{array}$ & 504115 & $\begin{array}{l}\text { MDP, Dimethacrylate resins, HEMA, } \\
\text { Vitrebond TM Copolymer, Filler, } \\
\text { Ethanol, Water, Initiators, Silane }\end{array}$ & $\begin{array}{l}\text { 3M ESPE St. Paul, MN, USA/Neuss, } \\
\text { Germany }\end{array}$ \\
\hline $\begin{array}{l}\text { Adper Singlebond } 2 \\
\text { (Adper Singlebond Plus in the USA) }\end{array}$ & N334650BR & $\begin{array}{l}\text { Bis-GMA, HEMA, dimethacrylates, } \\
\text { ethanol, water, photoinitiators, a } \\
\text { methacrylate functional copolymer } \\
\text { of polyacrylic and polyitaconic acids } \\
\text { and silica nanofiller }\end{array}$ & 3M ESPE Sumaré, SP, Brazil \\
\hline
\end{tabular}

*MPS, methacryloxypropyltrimethoxysilane (pre-hydrolyzed silane); MDP, 10-methacryloyloxydecyl dihydrogen phosphate; HEMA, 2-hydroxyethyl methacrylate; Bis-GMA, Bisphenol Adiglycidyl ether dimethacrilate.

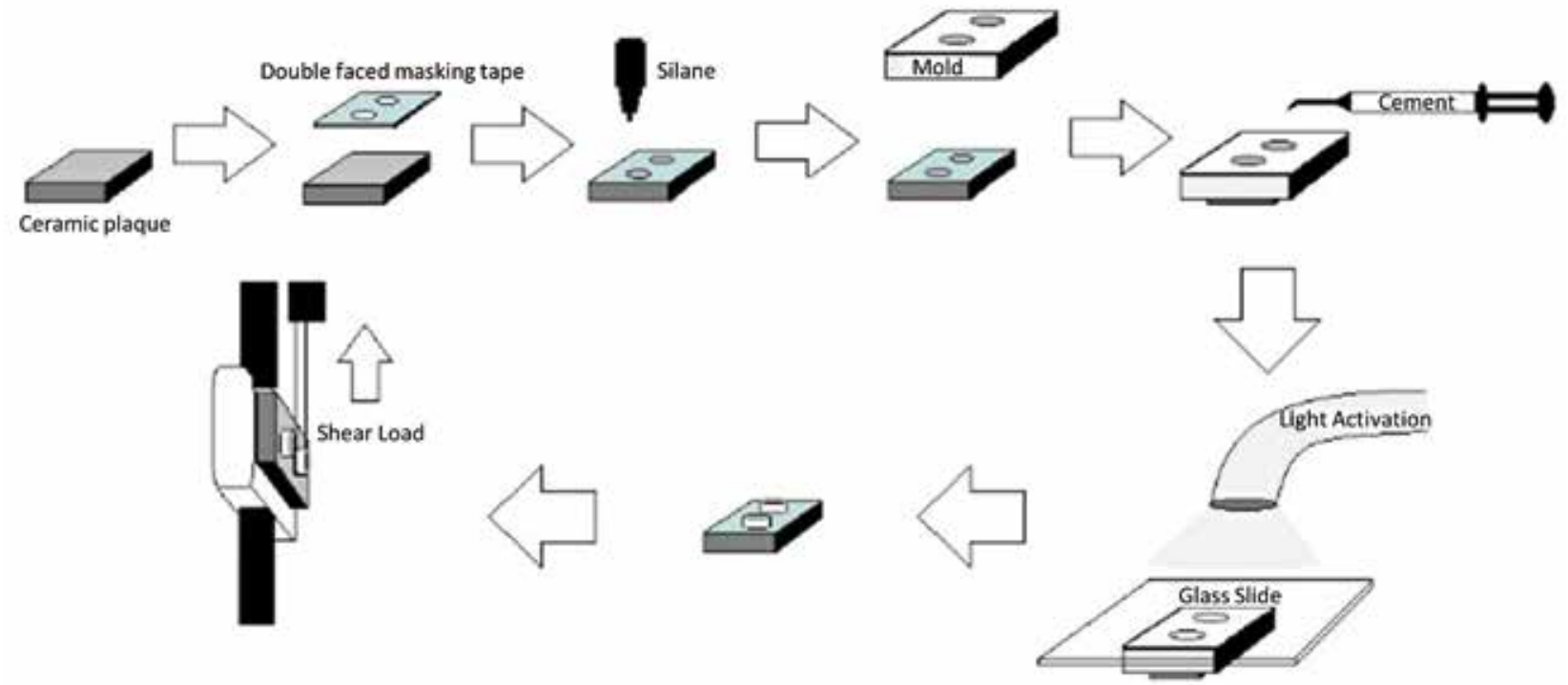

Figure 1. Schematic representation of the study set-up. 
Afterwards, plaques were randomly assigned to one of the following groups $(n=30)$ to be treated as follows: : (1) RCP-RelyX Ceramic Primer ${ }^{\circledR}$ (onebottle silane), (2) RCP+SB-RelyX Ceramic Primer and Adper Singlebond2 ${ }^{\circledR}$ (silane plus separated adhesive), (3) SBU-Scotchbond Universal ${ }^{\circledR}$ (silane- containing universal adhesive), (4) CP-Clearfil Ceramic Primer $®$ (silane/MDP primer), (5) NC-nosilane (negative control) and (6) PC-Previous HF etching $(5 \%, 20$ ) $)$ plus RelyX Ceramic Primer ${ }^{\circledR}$ (positive control). All treatment protocols for each experimental group are described on Table 2.

Table 2. Group division and treatment protocol.

\begin{tabular}{|c|c|}
\hline Groups & Treatment Protocol \\
\hline $\begin{array}{l}\text { RCP (RelyX Ceramic Primer-Conventional- } \\
\text { One bottle silane) }\end{array}$ & $\begin{array}{l}\text { No previous HF etching, application of Rely X Ceramic Primer in one coat, reacts for } 1 \\
\text { minute and air-dried for } 20 \mathrm{~s} .\end{array}$ \\
\hline $\begin{array}{c}\mathbf{R C P}+\mathbf{S B}(\text { RelyX Ceramic Primer plus } \\
\text { Adper Singlebond 2- Silane and separated } \\
\text { adhesive) }\end{array}$ & $\begin{array}{c}\text { No previous HF etching, application of Rely X Ceramic Primer in one coat, reacts for } 1 \\
\text { minute and air-dried for } 20 \mathrm{~s} \text { and also application of Adper Singlebond 2, also in one coat } \\
\text { and air-dried for } 5 \mathrm{~s} \text {. }\end{array}$ \\
\hline $\begin{array}{l}\text { SBU (Scotchbond Universal adhesive- } \\
\text { Silane-containing multi-mode adhesive) }\end{array}$ & $\begin{array}{l}\text { No previous HF etching, active application of Scotchbond Universal Adhesive for 20s, and } \\
\text { air-dried for 5s. }\end{array}$ \\
\hline $\begin{array}{c}\mathbf{C P} \text { (Clearfil Ceramic Primer- Silane/MDP } \\
\text { primer) }\end{array}$ & $\begin{array}{l}\text { No previous HF etching, application of Clearfil Ceramic Primer in one coat, reacts for } 1 \\
\text { minute and air-dried for } 20 \mathrm{~s} .\end{array}$ \\
\hline NC (Negative Control) & No previous HF etching, nor silane primer. \\
\hline PC (Positive Control) & $\begin{array}{l}\text { Previous HF etching }(5 \%, 20 \mathrm{~s}) \text { on ceramic surface and posterior application of Rely X } \\
\text { Ceramic Primer in one coat, reacts for } 1 \text { minute and air-dried for } 20 \mathrm{~s} \text {. }\end{array}$ \\
\hline
\end{tabular}

A silicon mold was placed on each treated glass ceramic plaque (each mold, containing two cylindrical-shaped compartments measuring $1 \pm 0.1 \mathrm{~mm}$ in diameter and $1 \pm 0.1 \mathrm{~mm}$ in thickness). Then, the resin cement was injected into each compartment on the treated ceramic surface using the manufacturers' auto-mixing tip and lightcured (Bluephase N, Ivoclar, Vivadent, schaan, Lichtenstein; light output: $1200 \mathrm{~mW} / \mathrm{cm} 2)$ for 20s. A 0,3 $\mathrm{mm}$ glass slide was placed between the light tip and the cylindrical resin cement specimen. The ceramic-plaque/resin-cement assemblies were removed from the molds after 5 minutes. The specimens were water rinsed, dried, and each group was randomly divided into two equal subgroups $(n=15)$, to be stored in distilled water at $37^{\circ} \mathrm{C}$ for 24 hours (24h) or 6 months (6mo).

After storage time elapsed, specimens were attached to a holding device with cyanoacrylate glue (Super Bonder Loctite, Henkel), placed on a universal testing machine (Instron 4411, Instron Corporation, Canton, MA, USA) and a shear load was applied to the base of the resin cement cylinder with a thin wire $(0.20 \mathrm{~mm}$ diameter), kept strictly parallel to the ceramic surface. The $\mu \mathrm{SBS}$ test was performed at a crosshead speed of 0.5 $\mathrm{mm} / \mathrm{min}$, using a $500-\mathrm{N}$ load cell. The results from each resin cement cylinder were obtained using Istron-Bluehill software and expressed in $\mathrm{MPa}$. As each ceramic plaque contained two resin cement cylinders, a $\mu$ SBS mean was obtained for each plaque $(n=15)$. Data were statistically analyzed by Two-Way ANOVA (Silane treatment vs Storage time) and Tukey Post-Hoc test at a significance level of $5 \%$.

For SEM evaluation, all specimens were mounted on aluminum stubs, sputter coated with gold/palladium (SCD 050; Balzers, Schaan, Liechtenstein) and then examined using a scanning electron microscope (JSM 5600 LV; JEOL, Tokyo, 
Japan) operating at $15 \mathrm{kV}$. Photomicrographs of representative areas of the fractured surfaces were taken at different magnifications for fracture pattern evaluation and then classified according to the following criteria: $A D-C C$, failure between ceramic and resin cement; $C$-AS, cohesive failure in adhesive system (when employed); C-CE, cohesive failure within the ceramic; $\mathrm{C}-\mathrm{RC}$, cohesive failure in resin cement and MIX, mixture of different kinds of fractures in the same specimen.

\section{RESULTS}

Two-way ANOVA revealed that both factors and their interaction resulted statistically significant $(p \leq 0.05)$. Tukey post-hoc test showed some differences among groups' means. A summary of $\mu$ SBS values are shown on Table 3 and graphically represented on Figure 2. PC obtained the highest $\mu$ SBS values (in MPa) after both storage times tested. After $24 \mathrm{~h}$ storage, groups $\mathrm{RCP}+\mathrm{SB}, \mathrm{SBU}$ and $\mathrm{CP}$ did not differ from the negative control group (NC). Only RCP and $\mathrm{PC}$ produced statistically higher values than NC after 24 hours storage. After 6 months, only PC showed higher values than NC. Representative photomicrographs form each groups' more prevalent failure patterns are shown from figure 4 to 9. Most groups exhibited a great prevalence of adhesive failure between ceramic and cement (AD-CC), except groups RCP-24h and PC (both, $24 \mathrm{~h}$ and $6 \mathrm{mo})$, in which cohesive failure in resin cement $(\mathrm{C}-\mathrm{RC})$ was more prevalent and groups $\mathrm{RCP}+\mathrm{SB}-24 \mathrm{~h}$ and SBU-24h which exhibited high prevalence of cohesive failure in adhesive system (C-AS).
Table 3. Microshear bond strength means (MPa) and standard deviations (SD), between glass-ceramic and resin cement, when submitted to different silane treatments and recorded after 24 hours and 6 months water storage.

\begin{tabular}{clclc}
\hline $\begin{array}{c}\text { Silane/ } \\
\text { Storage }\end{array}$ & \multicolumn{2}{c}{ 24 hours } & \multicolumn{2}{c}{$\mathbf{6}$ months } \\
\hline $\mathrm{RCP}$ & 19.73 & $(4.63) \mathrm{B}$ & 1.70 & $(2.15) \mathrm{DE}$ \\
$\mathrm{RCP}+\mathrm{SB}$ & 10.86 & $(3.62) \mathrm{C}$ & 0.84 & $(0.05) \mathrm{E}$ \\
$\mathrm{SBU}$ & 8.37 & $(4.33) \mathrm{CD}$ & 0.27 & $(0.06) \mathrm{E}$ \\
$\mathrm{CP}$ & 8.05 & $(3.62) \mathrm{CD}$ & 0.30 & $(0.04) \mathrm{E}$ \\
$\mathrm{NC}$ & 8.00 & $(2.51) \mathrm{CD}$ & 0.04 & $(0.01) \mathrm{E}$ \\
$\mathrm{PC}$ & 28.11 & $(2.44) \mathrm{A}$ & 19.10 & $(3.85) \mathrm{B}$ \\
\hline
\end{tabular}

Same capital letters indicates no significant differences (Tukey test, $\alpha=0.05)$.Abreviations: RelyX Ceramic Primer (RCP), RelyX Ceramic Primer + Adper Single Bond $2(\mathrm{RCP}+\mathrm{SB})$, Scotchbond Universal (SBU), Clearfil Ceramic Primer (CP), negative control (NC), positive control (PC).

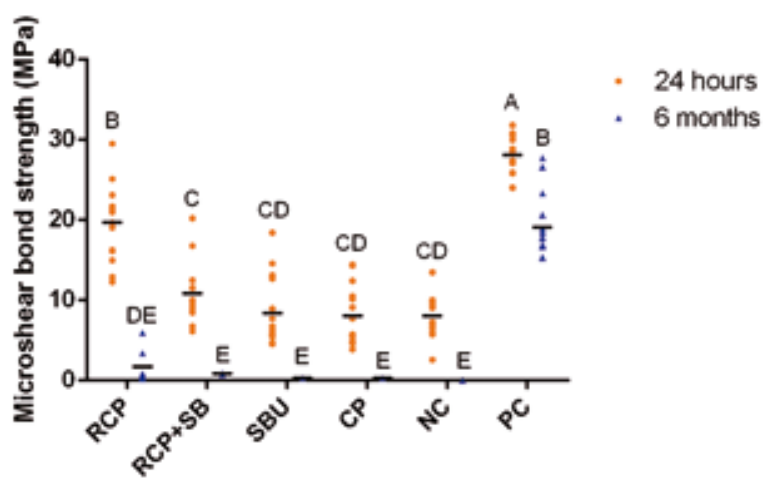

Silane Treatment

Figure 2. Distribution plot of microshear bond strength values ( $\mathrm{MPa}$ ) from all experimental groups. Each point (circle or triangle) represents the individual $\mu$ SBS mean from each specimen $(n=15)$, while the horizontal line on each data group, represents each group mean. Same capital letters represent no statistical differences among the groups (Tukey test, $\alpha=0.05$ ). Abreviations: RelyX Ceramic Primer (RCP), RelyX Ceramic Primer + Adper Single Bond $2(\mathrm{RCP}+\mathrm{SB})$, Scotchbond Universal (SBU), Clearfil Ceramic Primer $(\mathrm{CP})$, negative control (NC), positive control (PC). 


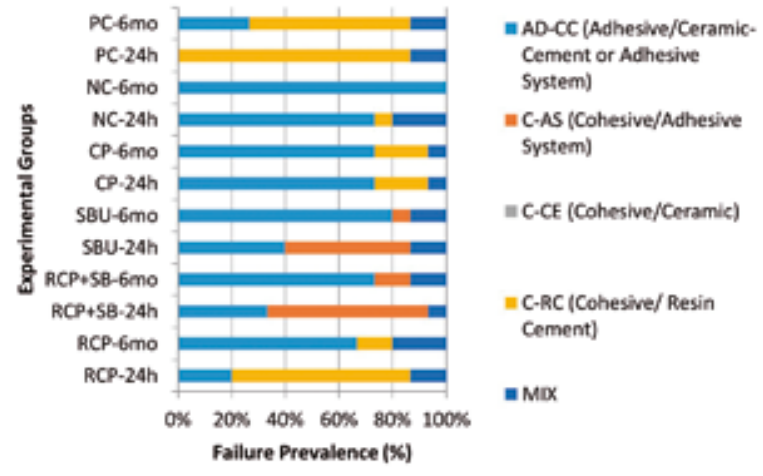

Figure 3. Failure mode prevalence from all experimental groups. Abreviations: RelyX Ceramic Primer (RCP), RelyX Ceramic Primer + Adper Single Bond 2 (RCP+SB), Scotchbond Universal (SBU), Clearfil Ceramic Primer (CP), negative control (NC), positive control (PC).
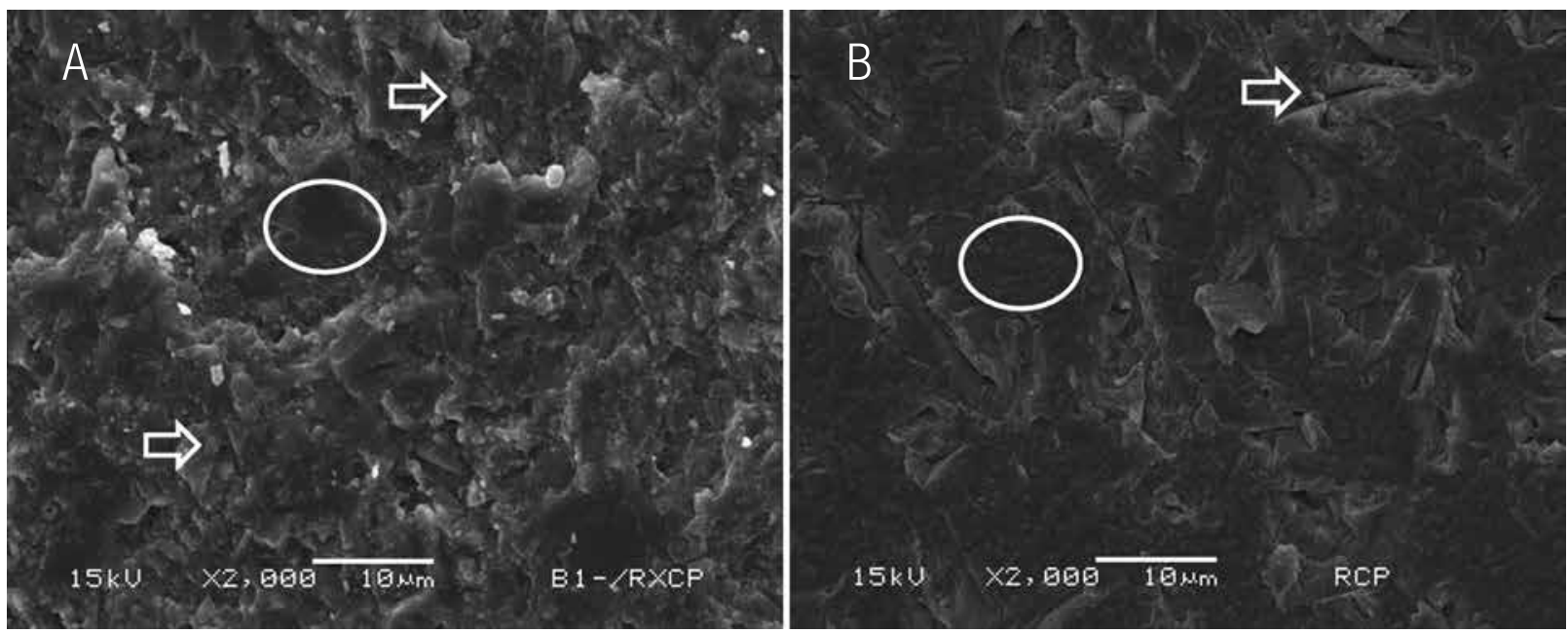

Figure 4. (A) Representative image exhibiting the more prevalent failure pattern from group RCP-24h on ceramics' surface (2000x), showing a cohesive failure in resin cement, where some resin cement particles (arrows) can be seen attached to the ceramic surface, also some clean ceramic areas can be noted (circle). (B) Representative image exhibiting the more prevalent failure pattern from group RCP6 mo on ceramics' surface (2000x), showing a clean ceramic surface (circle) with some irregularities (arrows), pointing that an adhesive failure between ceramic and cement occurred. 

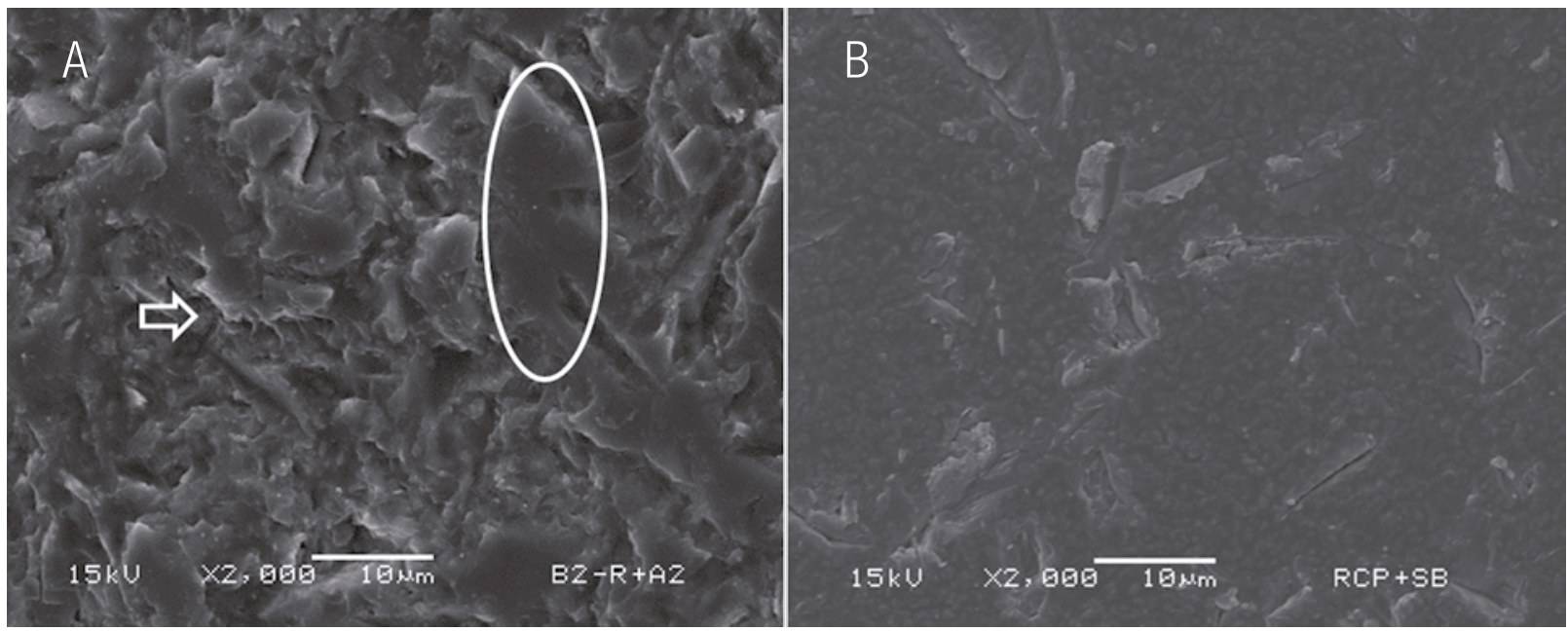

Figure 5. (A) Representative image exhibiting the more prevalent failure pattern from group RCP+SB-24h on ceramics' surface (2000x), showing a mostly cohesive failure in adhesive system, where some flat adhesive areas can be noted along with some depressions forming an irregular pattern in which the adhesive layer fractured. (B) Representative image exhibiting the more prevalent failure pattern from group RCP+SB-6mo on ceramics' surface (2000x), showing a clean ceramic surface, typical sign of an adhesive failure.
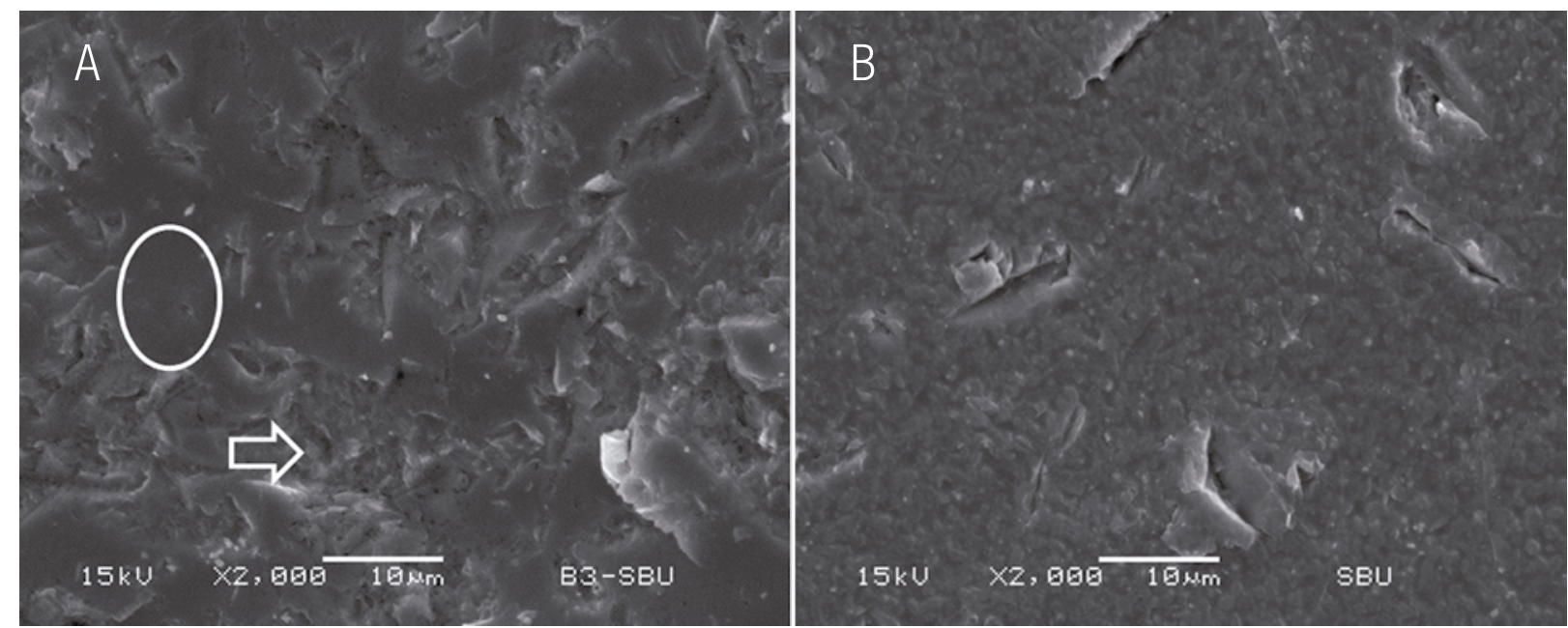

Figure 6. (A) Representative image exhibiting the more prevalent failure pattern from group SBU-24h on ceramics' surface (2000x), showing a mostly cohesive failure in adhesive system, where some flat adhesive areas can be noted along with some depressions forming an irregular pattern in which the adhesive layer fractured, a similar pattern as on Fig.5A. (B) Representative image exhibiting the more prevalent failure pattern from group SBU-6mo on ceramics' surface (2000x), showing a clean ceramic surface, typical sign of an adhesive failure, as shown on Fig.5B. 

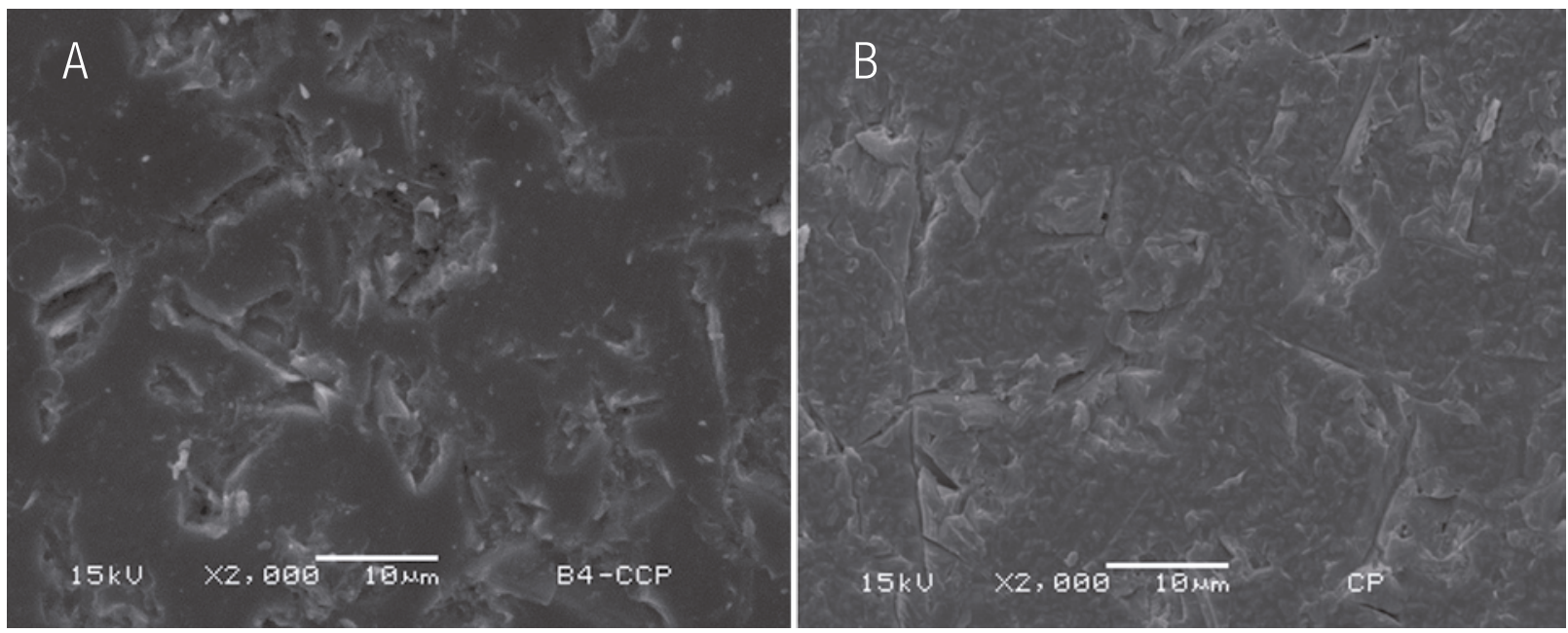

Figure 7. (A) Representative image exhibiting the more prevalent failure pattern from group CP-24h on ceramics' surface (2000x), showing a clean ceramic surface slightly covered by the primer in some areas, typical of a ceramic/cement adhesive failure. (B) Representative image exhibiting the more prevalent failure pattern from group CP-6mo on ceramics' surface (2000x), showing a completely clean ceramic surface, also indicating a ceramic/cement adhesive failure.
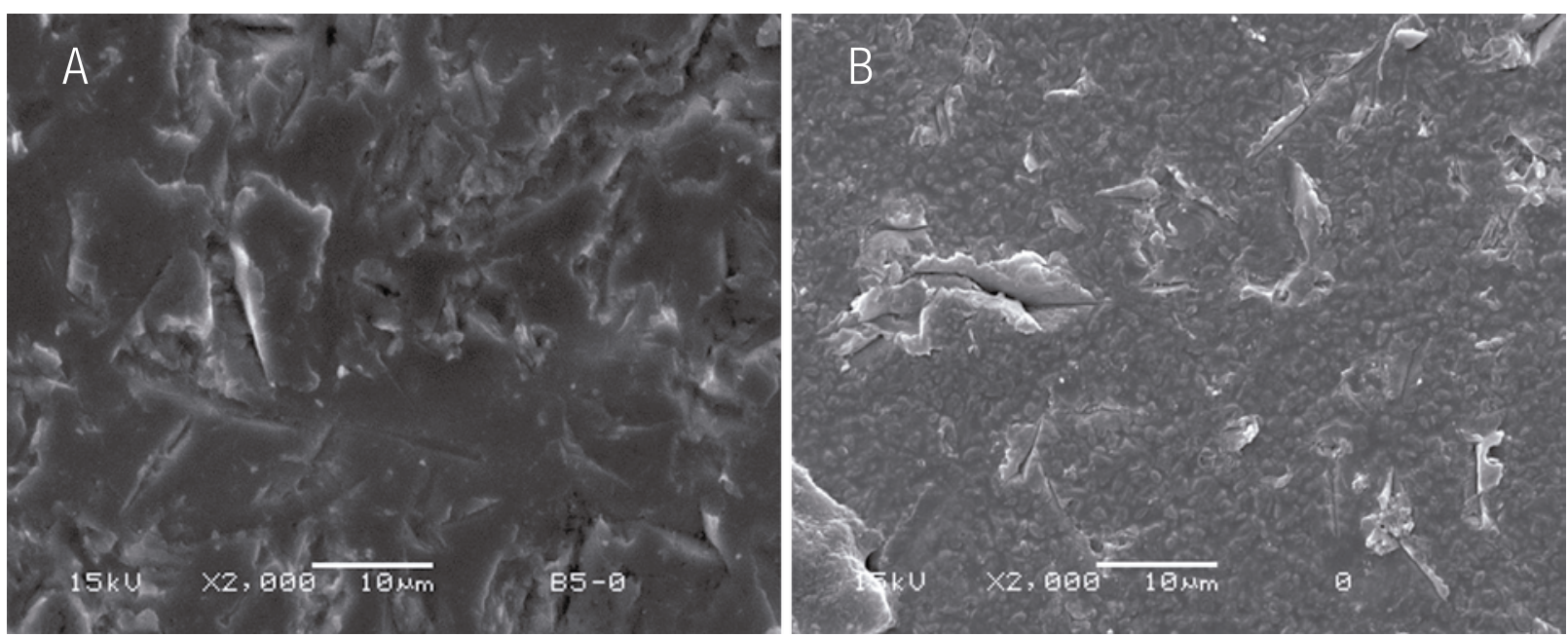

Figure 8. (A) Representative image exhibiting the more prevalent failure pattern from group NC-24h on ceramics' surface (2000x), showing a clean ceramic surface, corresponding to a ceramic/cement adhesive failure. (B) Representative image exhibiting the more prevalent failure pattern from group NC-6mo on ceramics' surface (2000x), showing also a ceramic/cement adhesive failure. 

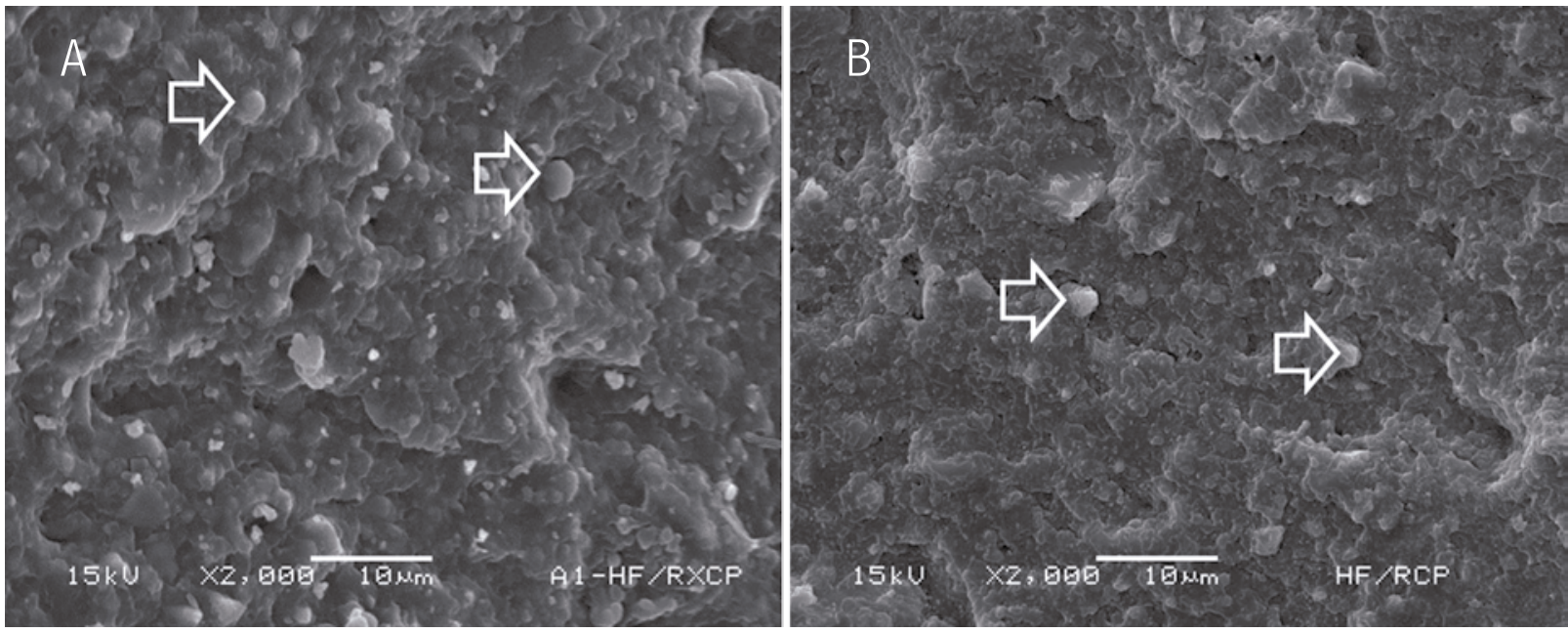

Figure 9. (A) Representative image exhibiting the more prevalent failure pattern from group PC-24h on ceramics' surface (2000x), showing a cohesive failure in resin cement, where a complete resin cement layer with some particles embedded (arrows) can be seen. (B) Representative image exhibiting the more prevalent failure pattern from group PC-6mo on ceramics' surface (2000x), showing also a cohesive failure on resin cement, but less profuse as on Fig.9A, probably consequence of resin cement leaching after aging.

\section{DISCUSSION}

The results of this in vitro study showed that different silane primers and storage time tested, significantly influenced ceramic/cement bond strength; consequently, the null hypothesis set in this study must be rejected.

With the intention of isolating silane primers' effect from the synergic improvement given by micromechanical strategy, is that all silane primers tested were used alone, without performing a previous hydrofluoric acid etching on ceramic surfaces. Nevertheless, the gold standard surface treatment for glass-ceramic was also included in this study as a positive control group $(\mathrm{PC})$, as well as a negative control group (NC), in order to compare them with the tested primers acting alone.

The best outcomes were obtained when employing both chemical and mechanical strategies together (PC) as ceramic surface treatment (Table 3 , Fig. 2). Thus, this treatment may still being considered as the gold standard treatment for this regard, as confirmed by previous works $[5,16]$. It seems, that the action of HF complements silane performance by producing not just surface irregularities but also improving ceramics' surface energy, rising resin cement wetting and producing an intimate contact between both materials. This issue may be confirmed by failure pattern analysis, in which PC demonstrated a high prevalence of cohesive failure in resin cement (Fig. 3), pointing that the weakest link on this system was not between ceramic and cement as failure occurred in the middle of resin cement layer as can be noted on figure 9 . It was previously demonstrated that higher bond strength values are associated with cohesive failure in luting agent [17-19]. This statement is in agreement with the present outcomes as a majority of such failure mode was observed on groups that performed best (Table 3, Fig. 2). Such association and similar failure analysis results on etched lithium-disilicate glass-ceramic were also obtained in previous studies $[17,20]$.

Although there is a general consensus on literature regarding the proper glass-ceramic surface treatment, some authors found that hydrofluoric acid etching is not necessary to improve ceramic/ cement bonding. Shimada et al. [11], Aida et al. [12] and Hooshmand et al. [13] found that HF etching did not improve ceramic/cement bonding, 
stating that just silanization of ceramics' surface may be enough to achieve a strong and longlasting bonding. Additionally, one of the primers tested on this study (CP) does not recommend performing HF etching on ceramics' surface before its application, as HF may be considered as a hazardous substance in some countries [10]. However, in the present investigation, only RCP produced statistically higher bond strength values when compared with the control group (NC) after 24 hours storage. No other primer tested, improved ceramic/cement bonding, not even CP which is recommended to be used without HF. This may be because RCP which is a conventional onebottle silane, may have created strong chemical links between ceramic and resin cement, enough to improve ceramic/cement bonding performance after 24 hours storage. Curiously, RCP+SB did not improve ceramic/cement bonding, even that this treatment employed the same silane primer as RCP group, which was the only treatment capable to achieve higher bond strength values than NC. The only difference between RCP and RCP+SB is the application of an adhesive system layer after silane coating. This treatment was employed in the present study $(\mathrm{RCP}+\mathrm{SB})$, as it is also recommended as ceramic surface treatment, as previous works found some benefits provided by adhesive coating on the ceramic surface, such as improved bond strength and wetting of the resin cement and stress absorbance [21-24]. In the present study, this technique did not improve ceramic-cement bonding, probably because adhesive acted as intermediate material between ceramic and resin cement, being the weakest element of the system. Adhesives normally contain lower filler particle concentration than resin cements $[25,26]$, reason why they (adhesives) may show lower mechanical properties. In the case of RCP, the failure occurred within the resin cement layer (Fig. 4A), conversely, on $\mathrm{RCP}+\mathrm{SB}$, it occurred along the adhesive layer (Fig. 5A), leading RCP+SB system to fail at lower load values than RCP.
In the case of the other silane treatments tested (SBU and CP), having other components such as hydrophobic/hydrophilic monomers and MDP mixed along with silane, may acts as a barrier for silane to achieve a profuse and intimate contact with the ceramic surface [27]. Other components mixed with silane may also obstruct the elimination of solvents and other byproducts and consequently, the formation of complete condensation reactions needed to form siloxane network [19]. Another issue that may decrease silane effectiveness is the silane layer thickness. Condensation reaction of silane is closely related to the thickness of the silane layer formed when applied, and to its concentration in the solution, having an important effect on the quality of bonding produced [28]. It has been suggested that silanes form three different oligomer layers when applied as a sole coat [29] and that just the one closest to the ceramic surface is necessary for bonding, the outermost layers cannot bond and may be detrimental [30]. By eliminating these layers and other by-products as water and ethanol, covalent bond formation can be promoted [28]. In light of those facts, SBU and CP may have had difficulties to establish stable condensation reactions to form siloxane network between ceramic and resin cement, as being composed of so many other ingredients than silane may have compromised its chemical action. Additionally, both primers (CP and $\mathrm{SBU})$ present lower pH than RCP (CP:3; SBU:2.7; $\mathrm{RCP}: 4.3)$ [2], which may cause a continuous hydrolyzation of silane molecules as they are hydrolyzed on acidic environments, consequently inactivating some part of the silane present on those solutions (SBU and CP), while material is not been used [31].

This scenario was worse after 6 months water storage, as not even RCP improved ceramic/ cement bonding. Only PC (gold standard treatment) succeeded on this task (Table 3, Fig. 2). Reason why it is likely to think that HF etching synergic 
effect is fundamental on powering silane action through time. Without an intimate contact or improved surface energy (provided by HF etching), silane primers alone, are not able to provide enough bond strength to integrate resin cement with ceramic surface. This can be confirmed with failure pattern analysis, as a huge prevalence of adhesive failure between ceramic and cement was noted on all groups stored by 6 months (Fig. 3, $4 \mathrm{~B}, 5 \mathrm{~B}, 6 \mathrm{~B}, 7 \mathrm{~B}$ and $8 \mathrm{~B}$ ), with the only exception of the only group employing $\mathrm{HF}$ and silane together (PC), which maintained the same failure pattern observed after 24 hours storage. Being low number of irregularities (normally produced by HF etching) on ceramic surface to produce mechanical interlocking between resin cement and glass-ceramic, lower bond strength may be expected after water ageing, even when using a silane primer.

In light of our results, it can be said that $\mathrm{HF}$ etching remains as a mandatory step before using any silane primer on glass-ceramics. Further researches focused on analyzing each silane primer performance on etched ceramic are encouraged.

\section{CONCLUSIONS}

Within the limitations of this in vitro study the following conclusions can be drawn:

- Only the conventional silane primer improved ceramic/cement bonding after short- term storage, after long-term storage, none of the primers tested succeeded on this task.

- The conjunction of HF etching and silane coating improved ceramic/cement bonding after shortand long- term storage.

- Performing HF etching on glass-ceramics, remains as a crucial step on silanization procedures of glass-ceramics.

\section{ACKNOWLEDGEMENTS}

The authors want to thank the University of Costa Rica, Brazilian CAPES and CNPq (grant \#:310650/2013-5) for supporting part of this research.

\section{REFERENCES}

1. Peumans M., Van Meerbeek B., Lambrechts P., Van Herle G. Porcelain veneers: A review of literature. J. Dent, 2000; 28; 163-177.

2. Ying Kei Lung C., Matinlinna J. P. Aspects of silane coupling agents and surface conditioning in dentistry: An overview. Dent Mater 2012; 28: 467-477.

3. Blatz M. B., Dent M., Sadan A., Kern M. Resin-ceramic bonding: a review of the literature. J. Prosthet Dent. 2003; 89: 268-74.

4. Scherrer S. S., de Rijk W. G., Belser U. C., Meyer J. M. Effect of cement film thickness on the fracture resistance of a machinable glass-ceramic. Dent Mater 1994; 10: 172-7.

5. Brentel S. A., Özcan M., Valandro L. F., Guimarães Alarça L., Amaral R., Bottino M. A. Microtensile bond strength of a resin cement to feldspathic ceramic after different etching and silanization regimens in dry and aged conditions. Dent Mater 2007;23: 1323-1331.

6. Chen J. H., Matsumura H., Atsuta M. Effect of etchant, etching period, and silane priming on bond strength to porcelain of composite resin. Oper Dent 1998; 23: 250-7.

7. Addison O., Marquis P. M., Fleming G. J. The impact of hydrofluoric acid surface treatments on the performance of a porcelain laminate restorative material. Dent Mater 2006; 16.

8. Dennerlein K., Kiesewetter F., Kilo S., Jäger T., Göen T., Korinth G., Drexler H. Dermal absorption and skin damage following hydrofluoric acid exposure in an ex vivo 
human skin model. Toxicology Letters 2016; 248: 25-33.

9. Cömlekoğlu M.E., Dündar M., Güngör M.A., Sen B. H., Artunç C. Preliminary evaluation of titanium tetrafluoride as an alternative ceramic etchant to hydrofluoric acid. Journal of Adhesive Dentistry 2009; 11: 447-53.

10. Safety Data Sheet/instructions for use, 1907/2006/EC,Article 31. Clearfil ${ }^{\text {TM }}$ Ceramic Primer, 01/04/2012. Kuraray Noritake Dental Inc., Okayama, Japan.

11. Shimada Y., Yamaguchi S., Tagami J. Microshear bond strength of dual-cured resin cement to glass ceramics. Dent Mat 2002; 8: 380-388.

12. Aida M., Hayakawa T., Mizukawa K. Adhesion of composite to porcelain with various surface conditions. J. Prosthet Dent 1995; 73: 464-70.

13. Hooshmand T., van Noort R., Keshvad A. Bond durability of the resin bonded and silane treated ceramic surface. Dent Mater 2002; 18: 179-88.

14. Matinlinna J. P., Lassila L. V. J., Özcan M., YliUrpo A., Vallittu P. K. An introduction to silanes and their clinical applications in dentistry. Int. J. Prosthodont 2004; 17: 155-64.

15. Blatz M. B., Sadan A., Martin J., Lang B. In vitro evaluation of shear bond strengths of resin to densely sintered high-purity zirconium-oxide ceramic after long-term storage and thermal cycling. J. Prosthet Dent 2004; 91: 356-62.

16. Kitayama S., Nikaido T., Takahashi R., Zhu L., Masaomi I., Foxton R., Sadr A., Tagami J. Effect of primer treatment on bonding of resin cements to zirconia ceramic. Dent Mater 2010; 26: 426-432.

17. Pollington S., Fabianelli A., Van Noort R. Microtensile bond strength of a resin cement to a novel fluorcanasite glass-ceramic following different surface treatments. Dent Mater 2010; 26: 864-872.
18. Hooshmand T., van Noort R., Keshvad A. Storage effect of a pre-activated silane on the resin to ceramic bond. Dent Mater 2004; 20: 635-642.

19. Shen C., Oh W. S., Williams J. R. Effect of post-silanization drying on the bond strength of composite to ceramic. Journal of Prosthetic Dentistry 2004; 91: 453-8.

20. Borges G. A., Spohr A. M., De Goes M. F., Correr-Sobrinho L., Chan D. C. N. Effect of etching and airborne particle abrasion on the microstructure of different dental ceramics. J. Prosthet Dent 2003; 89: 479-88.

21. Sundfeld Neto D., Naves L. Z., Costa A. R., Correr A. B., Consani S., Borges G. A., Correr-Sobrinho L. The Effect of hydrofluoric acid concentration on the bond strength and morphology of the surface and interface of glass ceramics to a resin cement. Operative Dentistry 2015; 40: 470-479.

22. Lastumaki T. M., Lassila L. V., Vallittu P. K. The semi-interpenetrating polymer network matrix of fiber-reinforced composite and its effect on the surface adhesive properties Journal of Materials Science: Materials in Medicine 2003; 14: 803-809.

23. El Zohairy A. A., De Gee A. J., Hassan F. M., Feilzer A. J. The effect of adhesives with various degrees of hydrophilicity on resin ceramic bond durability Dental Materials 2004; 20: 778-787.

24. Naves L. Z., Soares C. J., Moraes R. R., Gonçalves L. S., Sinhoreti M. A., CorrerSobrinho L. Surface/interface morphology and bond strength to glass ceramic etched for different periods Operative Dentistry 2010; 35: 420-427.

25. Material Safety Data Sheet, 2721. RelyX $\mathrm{X}^{\mathrm{TM}}$ Ultimate R. F., 08/02/11. 3M ESPE, St. Paul, M. N., USA.

26. Material Safety Data Sheet, 2721. Adper ${ }^{\mathrm{TM}}$ Single Bond Plus, 02/25/16. 3M ESPE, St. Paul, M. N., USA. 
27. Ikemura K., Tanaka H., Fujii T., Deguchi M., Negoro N., Endo T., Kadoma Y. Design of a new, multi-purpose, light-curing adhesive comprising a silane coupling agent, acidic adhesive monomers and dithiooctanoate monomers for bonding to varied metal and dental ceramic materials. Dent Mater 2011; 30 (4): 493-500.

28. Roulet J. F., Soderholm K. J., Longmate J. Effects of treatment and storage conditions on ceramic/composite bond strength. Journal of Dental Research 1995; 74: 381-7.

29. Ishida H., Koenig J. L. A Fourier-transform infrared spectroscopic study of the hydrolytic stability of silane coupling agents on E-glass fibers. J. Polymer Sci, Polymer Physics 1980; 18: 1931-1943.

30. Berg J., Jones F. R. The role of sizing resins, coupling agents and their blends on the formation of the interphase in glass fiber composites. Composite 1998; 29A: 1261-1272.

31. Yoshihara K., Nagaoka N., Sonoda A., Maruo Y., Makita Y., Okihara T., Irie M., Yoshida Y., Van Meerbeek B. Effectiveness and stability of silane coupling agentincorporated in 'universal' adhesives. Dental Materials 2016; 32: $1218-25$. 